\title{
Em defesa da educação pública: 30 anos da Constituição Federal
}

LEDA SCHEIBE*

Universidade do Oeste de Santa Catarina, Joaçaba-SC

ROSELANE FÁTIMA CAMPOS**

Universidade Federal de Santa Catarina, Florianópolis-SC

"A educação éo mais grave dilema educacional brasileiro. A sua falta prejudica da mesma forma que a fome e a miséria, ou até mais, pois priva os famintos e miseráveis dos meios que os possibilitam a tomar consciência de sua condição, dos meios de aprender a resistir a essa situação".

Florestan Fernandes $(1989,26)$.

"A educação popular e a reforma radical da educação estão vivas e constituem uma alavanca na relação dos trabalhadores e dos oprimidos com a transformação da sociedade brasileira. Por isso, 0 ensino público crescerá com a democracia. Os dois são interdependentes. Um fortalece o outro (e vice-versa)".

Florestan Fernandes $(1989,136)$.

$\mathrm{N}$ este ano de 2018 comemoramos 30 anos de promulgação da Constituição Federal, conhecida como Constituição Cidadã pelos avanços consideráveis nos direitos sociais. Todavia, observamos, nos últimos anos, o avanço de forças políticas conservadoras - no campo da economia, pela ascensão de políticas de austeridade fiscal ancoradas num receituário de corte ultraliberal e, no campo cultural, pela acelerada propagação de um ideário neoconservador, expressando-se, sobretudo, sob a forma de um fundamentalismo religioso cujas concepções e ações colocam em risco

* Doutora em Educação pela Pontifícia Universidade Católica de São Paulo, é professora aposentada da Universidade Federal de Santa Catarina. Atualmente é professora do Programa de Pós-graduação em Educação da Universidade do Oeste de Santa Catarina e editora da Retratos da Escola. E-mail: <lscheibe@uol.com.br>.

** Doutora em Educação pela Universidade Federal de Santa Catarina. É Professora Associada I da Universidade Federal de Santa Catarina, atuando no Curso de Pedagogia. Faz parte do Comitê Editorial da Revista Retratos da Escola. E-mail: <roselane.campos@ufsc.br>. 
desde o acesso aos conhecimentos científicos historicamente construídos, até discussões atuais em torno de preconceitos e opressões. O principal alvo desse "neoconservadorismo" tem sido a educação e as escolas públicas. Na educação, esse cenário tende a se agravar com o processo que levou à assunção de Jair Bolsonaro à Presidência da República, implementando um severo desmonte dos princípios democráticos que orientaram a Constituição de 1988. A nova conjuntura ameaça o futuro da educação pública no País e nos convoca à mobilização de todas as forças democráticas para a constituição de espaços de resistência às políticas retrógradas já em curso e que tenderão a ser aprofundadas.

No Dossiê anterior, demos inicio ao diálogo, procurando auscultar os processos em curso, a que denominamos de (des)democratização da educação brasileira. Como o próprio título indica, trata-se de um movimento marcadamente contraditório, eivado de litígios pelas forças políticas em presença. Todavia, os profissionais da educação, estudantes e movimentos sociais organizados têm mostrado forte vitalidade, erigindo barreiras às forças conservadoras que ascendem ao poder. Exemplo disso são os movimentos contra a chamada Lei da Mordaça, que em diversas partes do País têm lutado pela liberdade de cátedra e a livre circulação de ideias, princípios estes garantidos constitucionalmente. Perplexos por esses acontecimentos, rememoramos o que já interrogava Florestan Fernandes, em discurso histórico na então Assembleia Nacional Constituinte: "que educação escolar é possível se seus agentes são submetidos a padrões de tratamento e à estigmatização que degradam sua humanidade fundamental?" (1989, p. 134).

Neste novo número de nossa revista, última edição do volume 12 de 2018, trazemos o Dossiê Educação: 30 anos da Constituição Federal. Nosso propósito foi instigar os autores e autoras a revisitar os movimentos em defesa da educação pública ocorridos na década de 1980 e que culminaram em uma ampla agenda de reivindicações, muitas inscritas no texto constitucional posteriormente aprovado. Passados mais de 30 anos dos grandes movimentos que culminaram na Carta de Goiânia, aprovada na IV Conferência Brasileira de Educação (CBE, 1986), realizada por iniciativa da Associação Nacional de Pós-Graduação e Pesquisa em Educação (Anped), do Centro de Estudos Educação e Sociedade (Cedes) e da Associação Nacional de Educação (Ande), em Goiânia, evento que reuniu mais de cinco mil participantes entre os dias 2 e 5 de setembro de 1986, cabe-nos confrontar os tempos históricos e, além de repudiar todos os retrocessos, reafirmar as tarefas pendentes e necessárias à construção de uma educação pública, laica e de qualidade, em todos os níveis, para todas as brasileiras e brasileiros.

Para além do objetivo de refletir sobre as necessidades históricas que se apresentam, atualmente, em prol da educação pública, nossa intenção foi também a de apresentar às novas gerações de professoras e professores, que não vivenciaram as experiências do Período de Redemocratização pós Ditadura Cívil-Militar, o legado daqueles que contra esta lutaram.

Como nos lembra Benjamin (1985, p.224), “articular historicamente o passado não significa conhecê-lo 'como ele foi'. Significa apropriar-se de uma reminiscência, tal como 
ela relampeja no momento de um perigo". Inspirando-nos ainda neste autor, reafirmamos a necessidade de contar a história, de narrar o vivido, de intercambiar experiências humanas, cada vez mais silenciadas pelo peso das opressões e do aniquilamento subjetivo.

Relembramos aqui a força genuína que moveu, na década de 1980, a Campanha Nacional em Defesa da Escola Pública para Todos, cujos princípios foram expressos também na Carta de Goiânia e que se encontram, em larga medida, ainda pendentes. A reforma da educação proposta pela IV CBE à Assembléia Nacional Constituinte atinha-se a quatro princípios básicos:

1. A educação é direito de todo cidadão, sendo dever do Estado oferecer ensino público, gratuito e laico para todos, em todos os níveis;

2. O governo federal destinará nunca menos de $13 \%$ e os Governos dos Estados, do Distrito Federal e dos Municípios aplicarão, no mínimo 25\% de sua receita tributária na manutenção e desenvolvimento do ensino público e gratuito;

3. As verbas públicas destinam-se exclusivamente às escolas públicas, criadas e mantidas pelo Governo Federal, pelos Estados, Distrito Federal e Municípios;

4. A democratização da escola em todos os níveis deve ser assegurada quanto ao acesso, permanência e gestão (FERNANDES, 1989, p.136).

A Constituição de 1988, também conhecida como a Constituição Cidadã, expressão consagrada pelo deputado Ulysses Guimarães, foi sem dúvida um marco no processo de transição democrática do País. Segundo Paulo de Sena Martins (2018), esta constituição representou compromisso assumido pela Aliança Democrática, uma coligação que elegeu Tancredo Neves no Colégio Eleitoral. Em decorrência de sua morte, após sua eleição, assumiu o mandato o vice-presidente José Sarney. Ao fim do primeiro ano deste mandato, foi aprovada a Emenda Constitucional n 26, de 27 de novembro de 1985, que convocou a Assembléia Nacional Constituinte (ANC), que passou a se reunir a partir de 1987, após as eleições de renovação do Congresso Nacional em 1986. Há que destacar que foi então adotada a fórmula do Congresso Constituinte e não a de Constituinte Exclusiva (MARTINS, 2018).

Como nos informa Martins, os parlamentares-constituintes e a sociedade civil organizada foram os principais protagonistas do processo, que ganhou corpo nas subcomissões da ANC, "onde se moldou a alma da nova constituição-um documento que apontou para a construção do Estado Democrático de Direito, que tem por fundamentos a soberania, a cidadania, a dignidade da pessoa humana, os valores sociais do trabalho e da livre iniciativa e o pluralismo político" (2018, p.143).

Em artigo publicado pela Revista da Ande, no ano seguinte à aprovação da Constituição Federal, nosso colega educador, Carlos Roberto Jamil Cury (1989), foi enfático na afirmação de que o processo de elaboração do texto constitucional teve a 
participação da sociedade por meio de proposta e emendas enviadas por milhões de brasileiros e brasileiras, muitos acompanhando o andamento da sua discussão na TV e no rádio. No entanto, sugere o autor que muito mais do que princípios almejados, de modo integral, por determinados grupos sociais, vários deles foram deixados em aberto à efetivação e à direção de futuras legislações e, portanto, a forças de pressão articuladas a negociações políticas. Assim, segundo o autor ficaram explícitos não só o desejo das forças democráticas, caladas durante a Ditadura, mas também a volta de elementos oligárquicos e corporativos, tais como os que dizem respeito ao entendimento anacrônico da reforma agrária na Constituição, assim como o texto direcionado ao papel das Forças Armadas, o que redundou na militarização ou tutela militar sobre a sociedade civil.

Há, porém, conquistas materializadas na Constituição Cidadã, principalmente no que diz respeito aos direitos e garantias fundamentais que expressam tanto direitos e deveres individuais como coletivos: igualdade jurídica entre homens e mulheres; condenação da tortura; liberdade de consciência e expressão; liberdade de associação; garantia ao consumidor; racismo como crime inafiançável, entre outros. A educação, ao lado da saúde, do trabalho, do lazer, é reconhecida como direito social (CURY, 1989).

Tais princípios, possibilitadores da construção de uma sociedade livre, justa e solidária como garantia para o desenvolvimento da nação, foram amplamente debatidos pela Subcomissão da Educação, Cultura e Esportes, que integrava a Comissão Temática 8 - da Família, da Educação, Cultura e Esporte, da Ciência e Tecnologia e da Comunicação responsável por indicar o capítulo sobre a educação. O resultado oriundo da subcomissão, embora sujeito ao filtro de outros campos de discussão, gerou grande parte do conteúdo da atual Carta, contemplando, de alguma forma, a participação popular e da sociedade civil organizada, sob a liderança, no que se refere aos objetivos sociais e igualitários, do constituinte Florestan Fernandes. Como podemos verificar nos textos deste dossiê, a Constituição de 1988 é a matriz dos avanços sociais de muitas das conquistas da área da educação e, particularmente, da garantia do direito à educação.

Um forte segmento da sociedade civil pertencente ao campo educacional levou à Subcomissão de Educação a contribuição fundamental da Carta de Goiânia, que inaugura o nosso dossiê. No ano anterior ao início dos trabalhos constituintes, a IV CBE, que reuniu mais de cinco mil educadores, produziu uma série de propostas à Constituinte. Este documento histórico, após apresentar uma análise da conjuntura educacional no momento pré-constituinte, indicou aspectos que deveriam constar da nova Constituição. Os presidentes das entidades promotoras da CBE, Osmar Fávero (Anped), Elizabeth Camargo (Cedes) e Elba Siqueira de Sá Barreto (Ande), participaram de audiências públicas da Subcomissão, para defender as posições contidas na Carta de Goiânia.

Importante salientar que o documento que inicia o dossiê, além do diagnóstico da situação e diversos itens reivindicatórios, indica também a necessidade da elaboração de uma 
nova lei de diretrizes e bases da educação nacional a partir dos princípios inscritos na Constituição, cuja efetivação se deu apenas em 1996, após longas discussões e novas disputas.

Os artigos compilados no dossiê procuram também contribuir com os debates atuais acerca dos rumos da educação brasileira. A agenda da IV CBE, em parte assimilada pela Constituição Federal de 1988, encontra-se ainda inconclusa: quais, então, as tarefas históricas pendentes? "De qualquer maneira”, nos alertava Florestan Fernandes, "a nossa Constituição é uma constituição inacabada. Ela é uma sonata que não terminou." (1989, p.238; 1991, p.43). As exigências históricas do presente continuam a nos desafiar.

Os quatro primeiros artigos, que dão continuidade ao Dossiê, foram solicitados a colegas educadores que de alguma forma vivenciaram o processo da Constituinte, participando das discussões promovidas pelas entidades educacionais já citadas. $O$ primeiro deles é o artigo, Desafios à Educação em Direitos Humanos no Brasil após a Constituição 1988, de autoria de Erasto Fortes de Mendonça, que aborda os 30 anos de Constituição Brasileira e os 70 anos da Declaração Universal dos Direitos Humanos. Analisados a partir dos contextos históricos que lhes deram origem, o autor, afirmando o caráter civilizatório destes direitos, recupera a trajetória da educação em direitos humanos, como uma política pública no Brasil e finaliza destacando que "não há luta pelos direitos humanos sem conflitos, razão por que ser um defensor dos Direitos Humanos é estar na resistência e na contra hegemonia".

No segundo artigo, Educação laica na Constituinte: uma avaliação retrospectiva, Luiz Antônio Cunha nos apresenta os debates pré-constituintes em que se opuseram defensores da "laicidade" e do "confessionalismo", convergindo esta temática junto com os grandes debates da época que intencionavam construir uma pauta em prol da educação pública, laica e democrática para todos e em todos os níveis. Este tema inaugurou a IV CBE por meio de uma conferência apresentada pelo próprio autor do artigo. Cunha destaca também que a Carta de Goiânia, documento final da IV CBE, ao tratar da laicidade deu ênfase inédita ao tema em toda a história da educação brasileira.

Já a reflexão de Janete Maria L. de Azevedo e Maria da Salete Barboza Farias, ao abordar a evolução da gestão democrática da educação, emprega o conceito de democracia tal como proposto por Georges Burdeau. No artigo Democratização da gestão da educação: avanços e perspectivas, as autoras demonstram como o principio da gestão democrática se expressou na legislação e práticas de política, bem como os avanços e recuos nestas três ultimas décadas, sinalizando para as ameaças da atual conjuntura à ordem democrática. A luta consubstanciada na Carta de Goiânia é retomada pelas autoras, nos lembrando que "o debate sobre a gestão democrática não mais saiu de cena nesses 30 anos, o que se tornou um importante legado, mesmo que tenha estado mais presente na batalha das ideias e na legislação do que como método ou meio de atuação". Em suas reflexões finais, as autoras alertam para as "conquistas em risco", e apontam como "saída" a organização dos educadores em defesa da democracia na escola, apontando que é da capacidade de luta que emergem as 
resistências às medidas arbitrárias que podem emergir no próximo período com o governo a ser empossado em 2019.

Ainda na perspectiva de análise das lutas educacionais levadas a cabo no período pré e pós Constituição de 1988, assim como do movimento dos educadores que culminou com a Carta de Goiânia, Helena Lopes Freitas, em 30 anos da Constituição: avanços e retrocessos na formação de professores, faz uma análise aprofundada das políticas governamentais instituídas nas três últimas décadas e que visaram a formação de professoras e professores no Brasil. A reforma das licenciaturas, incluindo os cursos de Pedagogia, a diversificação das instituições formadoras e o crescimento sem precedentes do setor privado na oferta dos cursos de formação são objeto do olhar atento da autora. Segundo ela, as entidades da área educacional, tais como a Anfope, vêm firmando historicamente a necessidade de uma política de valorização e profissionalização dos educadores, condição essencial para uma educação básica emancipatória. Diante do atual cenário, nos alerta que "não há saídas fáceis, nem mesmo imediatas, em processos de perda de direitos, de autoritarismo e controle político e ideológico como os que se anunciam", clamando a todas as educadoras e educadores a permanecerem na luta contra as políticas regressivas que se aproximam.

Somando-se aos artigos mencionados, o texto intitulado O princípio da gestão democrática e sua aplicação no ensino público no Piauí, de autoria de Raimunda Maria da Cunha Ribeiro, nos apresenta os resultados de uma pesquisa sobre a implementação da gestão democrática em legislações emitidas por conselhos municipais de educação daquele estado. Tratando de uma extensa documentação, a autora conclui que dos 97 municípios piauienses, com sistema de ensino, 40 deles, ou seja, 41,2\%, não apontam na Lei de institucionalização qualquer dispositivo sobre gestão democrática do ensino público, tratando-se de uma "tarefa inconclusa". Apontando as contradições que constituem esses processos, aposta nas possibilidades, ainda que com grandes obstáculos a serem superados, de que as redes municipais inscrevam em seus regulamentos a gestão democrática como orientação, com seus efeitos espraiando-se não só nas redes, mas efetivamente também no chão das escolas.

Também analisando os efeitos pós-Constituição na área da educação e, em campo disciplinar específico - a educação física -, temos o artigo intitulado A educação física escolar a partir da Constituição Federal de 1988, de Matheus Bernardo Silva. O autor analisa os debates que atravessaram a Educação Física como campo disciplinar e prática pedagógica, no período pós-Constituição. Chama-nos a atenção para as disputas, para os avanços, ao mesmo tempo em que nos alerta para os riscos de retrocessos nos tempos atuais. Uma efetiva qualificação da prática pedagógica nessa disciplina dependerá, sobretudo, da capacidade de luta dos profissionais e de todos aqueles que lutam por uma educação pública de qualidade e democrática. Na perspectiva do autor, a mudança na educação física escolar, surge como possibilidade, o que implicaria em uma compreensão da especificidade da educação física escolar por meio das ciências humanas, a partir de uma crítica sistemática da influência das ciências naturais nesta área do conhecimento. 
Finalizamos o Dossiê com uma homenagem ao sociólogo e professor Florestan Fernandes, cuja atuação na Assembléia Nacional Constituinte em defesa da educação pública é por todos conhecida. A professora Marli Auras presta um depoimento emocionante, relembrando os tempos em que foi sua aluna. Traz em seu texto de memórias Tributo a Florestan Fernandes: reminiscências de um incomum, destemido e fundamental desafio passagens inéditas das aulas transcritas do professor, nos mostrando sua incansável capacidade de luta, de engajamento com seu tempo histórico. A autora finaliza seu depoimento nos lembrando que, mais do que nunca, a pertinência e a fecundidade do pensamento e da militância do professor Florestan Fernandes está a nos apontar uma direção como profissionais ou militantes. Devemos dar prioridade à solução dos problemas humanos, o que seria incompatível com a prioridade ao lucro. Dentre outras frentes, nos cabe defender a escola pública e gratuita para todos e todas e em todos os níveis.

Prestando essa justa homenagem, encerramos a apresentação do Dossiê, retomando o chamado para a luta em defesa da educação pública. Enfrentar os tempos de retrocessos que vivemos nos obriga à construção de redes de solidariedade e a atuação intelectual militante. Retomamos o legado da Carta de Goiânia que em seus parágrafos introdutórios assim dizia:

Os profissionais da Educação declaram-se cientes de suas responsabilidades na construção de uma Nação democrática, onde seus cidadãos possam exercer plenamente seus direitos, sem discriminação de qualquer espécie. Estão, por isso, empenhados em debater, analisar e fazer denúncias dos problemas e impasses da educação brasileira e, ao mesmo tempo, em colocar sua capacidade profissional e sua vontade política para a superação dos obstáculos que impedem a universalização do ensino público de qualidade para todo o povo brasileiro (IV CBE, 1986).

\section{Referências:}

BENJAMIN, W. Magia e técnica, arte e política: ensaios sobre literatura e história da cultura. São Paulo: Ed. Brasiliense, 1985.

BRASIL. Emenda Constitucional no 26, de 27 de novembro de 1985. Convoca Assembléia Nacional Constituinte e dá outras providências. Disponível em: http://www.planalto.gov.br/ ccivil_03/Constituicao/Emendas/Emc_anterior1988/emc26-85.htm.

CURY, Carlos Roberto Jamil. A educação e a nova ordem constitucional. Revista da Associação Nacional de Educação, Ande: São Paulo, v. 8, n. 14, 5-11, 1989.

FERNANDES, Florestan. O desafio educacional. Sao Paulo: Ed. Cortez, 1989.

MARTINS, Paulo de Sena. Carta de Goiânia. Cadernos ASLEGIS, Brasília: Câmara dos Deputados, n. 54, 141-148, 2018

IV CBE. Carta de Goiânia. Revista Educação e Sociedade, Campinas: CEDES, v. 25, 5-10, dezembro de 1986. 